University of Nebraska - Lincoln

DigitalCommons@University of Nebraska - Lincoln

1996

\title{
Scale issues in soil moisture modelling: problems and prospects
}

Rezaul Mahmood

University of Nebraska-Lincoln, rmahmood2@unl.edu

Follow this and additional works at: https://digitalcommons.unl.edu/natrespapers

Part of the Natural Resources and Conservation Commons, Natural Resources Management and Policy Commons, and the Other Environmental Sciences Commons

Mahmood, Rezaul, "Scale issues in soil moisture modelling: problems and prospects" (1996). Papers in Natural Resources. 1364.

https://digitalcommons.unl.edu/natrespapers/1364

This Article is brought to you for free and open access by the Natural Resources, School of at DigitalCommons@University of Nebraska - Lincoln. It has been accepted for inclusion in Papers in Natural Resources by an authorized administrator of DigitalCommons@University of Nebraska - Lincoln. 


\title{
Scale issues in soil moisture modelling: problems and prospects
}

\author{
Rezaul Mahmood \\ Department of Geography, College of Geosciences, \\ The University of Oklahoma, Norman, OK 73019, USA
}

\begin{abstract}
:
Soil moisture storage is an important component of the hydrological cycle and plays a key role in land-surface-atmosphere interaction. The soil-moisture storage equation in this study considers precipitation as an input and soil moisture as a residual term for runoff and evapotranspiration. A number of models have been developed to estimate soil moisture storage and the components of the soil-moisture storage equation. A detailed discussion of the implication of the scale of application of these models reports that it is not possible to extrapolate processes and their estimates from the small to the large scale. It is also noted that physically based models for small-scale applications are sufficiently detailed to reproduce land-surface-atmosphere interactions. On the other hand, models for large-scale applications oversimplify the processes. Recently developed physically based models for large-scale applications can only be applied to limited uses because of data restrictions and the problems associated with land surface characterization. It is reported that remote sensing can play an important role in overcoming the problems related to the unavailability of data and the land surface characterization of large-scale applications of these physically based models when estimating soil moisture storage.
\end{abstract}

Keywords: scale, soil moisture, hydrological cycle.

Published in Progress in Physical Geography 20:3 (1996), pp 273-291.

doi:10.1177/030913339602000302

Copyright (C) 1996 Arnold; published by SAGE Publications. Used by permission.

Published September 1, 1996. 


\section{Introduction}

Soil moisture is an important component in the hydrological cycle, specifically in the planetary water balance. Soil moisture storage plays a key role in land-surface-atmosphere feedback processes. Thus, it is necessary to obtain a better estimate of soil moisture storage to understand the processes involved within the hydrological cycle. Soil moisture models can be used to estimate moisture storage. The fundamental equation for soil moisture modelling can be expressed as follows:

$$
\Delta \mathrm{SM}=\mathrm{P}-\mathrm{ET}-\mathrm{R}
$$

where SM is soil moisture storage, P is precipitation, ET is evapotranspiration and $\mathrm{R}$ is runoff. The runoff term includes surface runoff, subsurface lateral flow and seepage to groundwater. The soil moisture budget can be modelled totally from a hydrological standpoint to calculate runoff (cf. Loague and Freeze, 1985) or it can be modelled as a component of land-surface-atmosphere interaction processes (cf. Milly, 1992); it is also possible to combine both (cf. Mather, 1978). An important issue that needs to be addressed before taking any of these routes is to determine the model's scale. The scale of application determines the complexity of the physical-chemical-biological processes within the models. This article will discuss various issues related to the scale of soil moisture budget modelling. These include the determination of the physical processes and controlling factors of runoff and evapotranspiration at different scales, their modelling and the problems associated with measurement.

It is known that the role of the various controlling factors and associated processes varies at different scales. Klemes (1983) noted that the scale of physical processes is not arbitrary, and their range is not unrealistically continuous. Problems associated with interpolating small-scale controlling factors and dominating processes to the large scale frequently demonstrate this. Models that deal with the estimation of runoff and evapotranspiration also commonly inherit this problem. As a result, modelling at different scales has become an important issue in recent years. The scale of application determines how much complexity should be allowed within the models. 
Over the last few decades, our understanding of biophysical-chemical processes has expanded at an astonishing rate. Owing to the increase in computing power during this period, it became possible to integrate these processes into the model to estimate soil moisture. Although this leads to a significant improvement in replicating the realworld processes within the model, model validation and application at different scales became a significant problem. The former is dependent on high-quality and high-resolution data while the latter is dependent on understanding the various dominant processes at different scales. The following sections will focus on the processes that are important for the two components (runoff and evapotranspiration) of soil moisture modelling at different scales, and related issues. Although runoff and evapotranspiration are closely connected and interdependent, they will be treated separately for a clearer understanding of the processes involved. Detailed model equations are provided in the Appendix.

\section{Runoff}

Runoff is largely dependent on the intensity of rainfall, the infiltration capacity of the soil, antecedent soil water condition, soil type, land use and physiography. If rainfall intensity exceeds infiltration capacity, surface runoff occurs (Dunne and Leopold, 1978). Gravity flow and capillary forces significantly influence infiltration capacity. Both these processes are largely dependent on the soil type. Gravity flow is a dominant controlling factor where soil is coarse or pores are large, while capillary forces are important controlling factors where soil is fine or pores are very small. Antecedent soil moisture also determines how much water is going to pass through the soil and thus controls saturation of the soil (which leads to surface runoff).

Vegetation cover and land use influence infiltration capacity and thus the surface and subsurface flow of water. Types of vegetation determine the depth of the root zone and the moisture-holding capacity of the root zone. Dense canopy cover protects soils from rain-packing and thus increases the infiltration capacity of the soil. Dense canopy cover also supplies abundant humus which does not allow rainfall intensity to exceed infiltration capacity. It is also found that replacing 
forests with agriculture (which does not cover the land fully and does not contain a higher amount of organic matter) drastically reduces infiltration capacity and thus increases runoff. Urban land use sharply increases surface runoff. A sloped surface partly controls surface and subsurface runoff, and enhances runoff through gravitational pull. Furthermore, groundwater storage and subsurface runoff influence surface runoff. Local geology, soil type and climate determine the depth of the groundwater table. Groundwater storage influences the soil moisture content of overlying soil layers through capillary flow, which is dependent on the soil texture. This process eventually modifies surface runoff and infiltration capacity by changing soil moisture content. Furthermore, surface runoff determines how much water is left for evapotranspiration and soil moisture storage. Thus, it is clear that various soil-water-related processes are interconnected and interdependent.

As mentioned previously, the question is, how much process detail should be incorporated into the model for soil moisture estimation? The details of the model will depend on the scale of application. For a small-scale study, it is sometimes possible to record most of the small variations of the different controlling factors. For example, Loague (1992a; 1992b) developed a soil-water content data set composed of nearly 25,000 measurements made at a $100 \mathrm{~m}^{2}$ basin of Chikasha, Oklahoma. He estimated the impact of soil water on runoff by constructing a "quasi-physically based rainfall-runoff model." This model provided improved estimates of peak flow (however, the timing of the peak flow was not satisfactory). It would be very difficult to use this model satisfactorily for a large basin because of the impossible task of gathering such high-resolution data. In such a case, simplifying the model's assumptions and its underlying physics is the answer.

Numerous extensive smaller-scale studies have been performed using sophisticated physically based models. For example, Peck et al. (1977) developed a scaling factor to estimate the effects of spatial variability of soils in water balance modelling. They developed this method to interpolate soil properties from fewer observations. The authors estimated the soil properties of the Branch watershed of Tennessee by using the scaling factor. Finally, they used these results in a water balance model that calculates, among other things, runoff. They claimed that the water budget components were in close agreement with the 
simulated spatial soil-water variability. In subsequent years, scaling theory has been used frequently in various water balance and rainfall-runoff models for small basins to estimate the effects of soil heterogeneity on soil-water content (e.g., Sharma and Luxmoore, 1979; Luxmoore and Sharma, 1980; Clapp et al., 1983). Similar modelling studies by Milly and Eagleson (1987), Loague (1990) and Loague and Gander (1990) in small basins have estimated the effects of porosity and the infiltration rate on runoff and water balance. Hughes (1994) applied four "deterministic" models (namely, VT1, RAFLES, P-Export, and Pitman) to estimate runoff from a $0.18 \mathrm{~km}^{2}$ grassland catchment in the Eastern Cape Province of South Africa. Model parameters were determined from the physical characteristics of the catchment. Model predictions were satisfactory.

In the light of the above discussion, the following questions can be asked: is it possible to collect data on the worldwide infiltration rate for model calibration, or is it possible to include characteristics of capillary flow under various soil types for the whole planet, or is it possible to model the effects of all the different types of vegetation cover on runoff for the whole globe? The answer is no. The land surface is very heterogeneous at the large scale, which makes it impossible to capture its complexity within models for large-area studies. It has also been questioned whether we can extrapolate the results from small-scale studies to the larger regional or global scale. Again, the answer is no. Pilgrim et al. (1982) and Pilgrim (1983) identified the problem of transferring results from small basins to large basins. Pilgrim (1983) noted that even if infiltration characteristics are the same in two basins, different infiltration responses owing to the varying sizes of the basins require separate parameterization. For example, the water-storing capacity of the larger basins will be greater than the smaller basins. As a result, runoff response will vary at basins of different sizes under similar precipitation conditions. Pilgrim (1983) concluded that transferring results from smaller-scale studies to the regional or the global is dangerous and counterproductive. He also noted that this may create a major impediment to the understanding of the relationships among processes. Thus, we need to take a different modelling approach in estimating runoff for soil moisture calculation. This includes the need to identify dominating processes and their responses under different conditions at the regional and global 
scale to develop proper parameters. Gleick's (1987) approach can be adopted as a first step in this direction. He applied a modified Thornthwaite (1948) method to the Sacramento basin to estimate water balance. One of the model outputs was runoff. The size of the Sacramento basin is $41,000 \mathrm{~km}^{2}$. As a result of the distinct characteristics of the climate and vegetation in the upper and lower basin due to elevation change, he introduced different assumptions into the model for these two subbasins. The two-basin model run provided a better, physically plausible estimate of runoff.

For global-scale runoff estimates, Thornthwaite's (1948) water budget model has been widely accepted as a standard method. This method assumes that runoff only occurs if excess soil moisture is available after evapotranspiration demand has been met and soil moisture recharge has been completed (Willmott et al., 1985). Legates and Willmott (1995) noted that the problem with the Thornthwaite method lies in the assumption that runoff occurs as a residual of water budget. As a result, the inaccuracies associated with the measurement of components of the water budget (such as evapotranspiration and soil moisture) or poor quality of the input data set and/or insufficient parameterization can be compounded in runoff estimates. Regardless of these difficulties, the Thornthwaite model is probably the most satisfactory runoff estimation method available for the large, regional scale to global-scale application. This method is relatively simple and the data requirement is not complex. The integration of a relatively detailed (but not too complex) and realistic description of biophysical-chemical processes into this method would make it an ideal tool for large-scale runoff estimation.

\section{Evapotranspiration}

Modelling evapotranspiration (ET) for soil moisture estimates at different scales can be as difficult as calculating runoff. ET is primarily controlled by solar radiation, the supply of water and atmospheric humidity (or vapor pressure deficit). Other important controlling factors are stomatal resistance, aerodynamic resistance and surface resistance. Soil characteristics also play an important role by determining the water-holding capacity at the surface level and at the root zone, 
which in turn influences the water available for plants to transpire. As in modelling runoff, the scale of study may determine the degree of complexity that should be introduced into the ET model without weakening its theoretical foundation or simplifying its biophysicalchemical processes.

A large number of highly sophisticated models that replicate detailed biophysical processes have been developed over the past few decades. In most cases these are referred to as "physically based" models. In this discussion, these models are grouped into two categories, namely, combination and eddy-diffusion-type ET models. Models in the combination category integrate energy balance and aerodynamic terms. These models estimate ET by calculating the supply of energy and the "turbulent transport of water vapor from an evaporating surface" (Rosenberg et al., 1983: 248). Penman (1948) was the first to develop this type of model, and Monteith (1965) proposed some major improvements to Penman's method by adding resistance terms. This is why the combination-type equations developed during subsequent years are known as Penman and Penman-Monteith equations. Owing to the wide variety of combination-type ET models, they can be further categorized into four subgroups, namely, energy balance, interception, single layer and multilayer models.

Energy balance equations were the first step in developing a physical basis for ET. Penman's (1948) method of ET estimation is the classic example. His method successfully integrates physical terms into ET estimation. The data requirements for his method are simple and, as a result, it is the most widely used physically based model. However, it has been criticized for underemphasizing the importance of ventilation relative to radiation in maintaining regional evaporation, and also for underestimating ET under strong sensible heat convection. The latter criticism is probably linked to the fact that this model was initially based on cool and moist climatic data.

Van Bavel (1966) and Priestley and Taylor (1972) developed similar energy balance methods. Surface roughness length plays an important role in the ET estimation system constructed by van Bavel. Since this model is sensitive to windiness, it underestimates ET rate under calm conditions and overestimates ET rate under strong winds. The distinct advantage of the Priestley and Taylor (1972) method is that it can be used with satellite data to calculate reference crop ET for large 
remote areas where data are not available. It also provides good ET estimation in humid areas.

Interception models are characterized by the introduction of the concept of interception loss during a storm. Thom and Oliver (1977) modified the Penman (1948) method to develop a model for estimating actual ET. They used atmospheric stability terms extensively in their method. However, this model has been criticized because the surface resistance term is not totally related to stomatal resistance. Gash (1978) modified the Thom and Oliver (1977) method to provide separate estimates of interception loss. Unfortunately, this model is only applicable to tall vegetation. Later, Gash (1979) proposed a model for interception loss from tall crops that omitted evaporation from tree trunks. In this model, real rainfall is represented by a series of discrete storms. These storms are separated by a time interval that is sufficient to dry up the canopy and tree trunks.

Rutter et al. (1971) developed a model to estimate rainfall interception in forests. This model can calculate a running water balance during a period of rainfall, throughfall and ET. It can also estimate changes in canopy storage. This method made an important contribution to calculating interception loss from wet and partially wet surfaces. Despite the model's success, it has been criticized for its failure to formulate and adopt an algorithm that could deal with the changing depth of vegetation and the resulting variation in interception and evaporation loss. Sellers and Lockwood's (1981) multilayer model attempted to overcome some of these weaknesses.

Single-layer combination-type models assume that "all the components of element of vegetation are exposed to the same microclimate" (Shuttleworth, 1991: 112). In other words, these models treat the whole boundary layer as a single layer. In these models, aerodynamic and stomatal resistance control ET. Monteith (1965) made the first successful breakthrough in developing a single-layer model which combines energy and aerodynamic terms. Monteith used resistance terms extensively in his model. His method estimates relative evaporation rates from dry and wet surfaces. It assumes that the relationship between transpiration and leaf area is influenced by the closure of stomata when they are shaded from sunlight. Unlike many established models, Monteith raised the important question of advection. Although this method made remarkable progress by incorporating 
several very important plant physiological phenomena that control ET, it failed to address the influence of soil surface resistance, horizontal fluxes, evaporation from tree trunks, interception loss and the three-dimensional nature of various ET-related processes.

A much improved version of the single-layer model for ET-interception was developed for urban areas by Grimmond and Oke (1991). This model is based on the methods developed by Penman (1948), Monteith (1965), Rutter et al. (1971) and Shuttleworth (1978; 1979). The Grimmond and Oke (1991) method has been satisfactorily applied to urban areas, where it has successfully integrated an anthropogenic heat-flux term and a turbulent source-area concept, and has estimated ET from wet, partially wet and dry surfaces.

The multilayer ET models divide the atmospheric boundary layer and soil surface into several horizontal layers, estimate the interception of solar and thermal radiation, and calculate sensible and latent energy flux for each layer. Shuttleworth (1991) noted that these models are the best available methods for estimating ET provided that complex data requirements are fulfilled and submodels are available. Multilayer models can be divided into two groups. One includes the models that divide the atmospheric boundary layer and soil surface into several layers, and integrate these explicitly into the model (e.g., Sellers and Lockwood, 1981; Shuttleworth and Wallace, 1985; Choudhury and Monteith, 1988). The second group includes models that subdivide only the canopy layer into several horizontal layers, and do not integrate the layered soil surface as explicitly as the previous group (cf. Waggoner and Reifsnyder, 1968; Sinclair et al., 1976).

Shuttleworth and Wallace's (1985) multilayer model estimates evaporation from sparse crops using a Penman-Monteith-type combination equation. This model divides the boundary layer into several layers: the soil surface; the layer between soil surface and mean canopy layer; the mean canopy layer; and the layer between the mean canopy layer and the reference height above the canopy. It also includes the concepts of aerodynamic resistance and canopy resistance, and the less well-known concept of bare soil resistance. These resistance terms can be applied at different horizontal layers (e.g., substrate surface resistance; bulk boundary layer resistance between the vegetation surface and the canopy air stream; transfer resistance between the mean canopy layer and a reference height; and transfer 
resistance between the substrate surface and the adjacent boundary layer). Two Penman-Monteith-type equations have been devised, one for the latent heat flux from the substrate, and one for the plant canopy. Summation of these two provides values for the whole boundary layer. The weakness of this model is its failure to address the threedimensional nature of the various boundary processes. Also, Shuttleworth and Wallace (1985) arbitrarily divide the boundary layer into "the crop" and "the soil" layer. The model considers only the soil beneath the vegetation. For row crops, it does not allow any room to deal with the soil between the rows. A similar model has been developed by Choudhury and Monteith (1988), where the canopy layer and soil layer are divided into two more layers. Energy flux is defined by resistances. This model is only applicable to homogeneous surfaces. Choudhury and Monteith (1988) assume a small gradient for lateral fluxes, overlooking horizontal fluxes - one of the major weaknesses of their model. Compared with integrated crop and soil multilayer models, crop-only multilayer models are less realistic in their assumptions. For example, Waggoner and Reifsnyder (1968) assume a soil surface that does not exchange water or sensible heat with the adjacent atmospheric layer. This assumption affects the model's estimation of latent energy flux by influencing vapor pressure and resistance terms.

Eddy diffusion models incorporate the effects on evapotranspiration of turbulent transfer of water vapor. The theoretical basis of these models and their assumptions offered a new direction for understanding ET-related processes. Some of the important contributions in eddy diffusion modelling were made by Garratt and Hicks (1973), Rosenberg et al. (1983), Butler (1986), Myers and Paw (1987), Massman and Dijken (1989) and Wilson (1989).

Myers and Paw (1987) included the latent heat of vaporization, the density of the air, the saturation-specific humidity of the leaf temperature and the specific humidity of the air - which all play important roles in eddy diffusion. Their model validated the flux-gradient relationship above the canopy and also turbulent transport within the canopy. Additionally, Myers and Paw (1987) included resistance terms in their model. However, although the resistance terms are not a primary determinant of ET in Myers and Paw's model, the model is an important development in reconciling combination- type and eddy-type diffusion models. Similarly, Rosenberg et al. (1983), Butler 
(1986) and Massman and Dijken (1989) integrate resistance terms. As expected, diffusion terms are explicitly added to these models. Compared with these, Wilson (1989) does not address resistance terms at all. The theoretical basis of this model is dependent on the assumption of the turbulent transport of water vapor. Wilson criticized combination methods because of their "failure" to address the process of turbulent diffusion.

Legg and Monteith (1975) criticized eddy diffusion models for their inability to comprehend the role of physiological resistance in the ET process. Since eddy diffusion models provide a good description of the turbulent transport of water vapor, and since combination-type methods offer a reasonable description of the physiological control of the ET process, a combination of both approaches would be an ideal basis for ET modelling.

In general, both combination and eddy diffusion type models are based on theoretically sound assumptions. But the question is, again, are these models suitable for large-scale applications? The answer, again, is no: all these models were tested and applied to very small areas, and are thus largely suitable for small-scale applications. Moreover, the assumptions and parameterization schemes of these models are only suitable for such applications. It is, for example, impossible to collect data for stomatal resistance, aerodynamic resistance and soil surface resistance of the various types of soil under variable climatic and soil-water content conditions; for the leaf area index of the various types of vegetation; for the interception loss from the different types of vegetation under storms of differing intensity and character; and for the surface roughness length for large basins/regions or for the globe to calibrate and validate the models. Despite their sophistication, these models adopt a "big leaf" approach for stomatal resistance estimation which assumes identical stomatal resistance for all types of vegetation. Such an assumption clearly implies the unavailability of data not only for macroscale but also for microscale study. Thus, Shuttleworth (1991) is correct when he suggests that, despite the superiority of multilayer and single-layer models for ET calculation, the lack of short-term meteorological data and the unavailability of a stomatal resistance submodel is a major impediment to the application of such models (even for the small scale). He noted that the calculation of a standard evaporation rate and its subsequent modification by a 
crop factor would provide a useful solution to this problem.

Thornthwaite's (1948) ET estimation method is one of two means towards solving this problem. Several large-scale studies have been performed using this method or a modified version of it (e.g., Willmott et al., 1985; Serafini and Sud, 1987; Mintz and Walker, 1993). Willmott et al. (1985) used Thornthwaite's ET method to estimate global potential ET in the process of calculating the planetary water budget. Legates and Willmott (1995) noted that this method's performance is relatively satisfactory when compared with the Jensen-Haise, Priestley-Taylor, and Penman methods. However, Willmott et al. (1985) claim that Thornthwaite's method systematically underestimates potential ET when compared with lysimeter records. Legates and Mather (1992) also point out that, owing to the model's biased precipitation estimates, and in order to calculate correct streamflow and runoff estimates, the method must underestimate potential ET. Willmott (1984) suggests that, by using a simple linear regression analysis, it is possible to remove the model's systematic bias and hence attain a relatively satisfactory estimate. Another drawback in the method lies in its calculation of potential ET under nonstressed conditions. To overcome this, Dooge (1992) introduced a correction factor, and Mintz and Walker (1993) further refined the model by introducing an "equivalent temperature" component to estimate potential ET. Mintz and Walker also found that the true potential ET decreased from $6.2 \mathrm{~mm}$ day to 5.1 $\mathrm{mm}$ day (the former using a shelter-high temperature).

Serafini and Sud (1987) used a modified version of the Thornthwaite method to estimate global ET. They modified the moisture availability function of Nappo's (1975) ET equation (see the Appendix). Serafini and Sud achieved satisfactory results in estimating planetary ET. Manabe (1969) used a modified version of Budyko's (1956) method of ET calculation, the Geophysical Fluid Dynamics Laboratory (GFDL) general circulation model (GCM), to estimate the ET and soil moisture of the globe. Delworth and Manabe (1988) report that there are notable differences between potential ET estimated by the GFDL GCM and the very rough approximations calculated by Budyko's method for the summer months (June-September). They also have found that the GFDL GCM application resulted in an ET estimate of 1-3 $m$ for the southern USA. Rind et al. (1990) calculated an ET estimate of more than $3 \mathrm{~m}$ for the same season and region. The application of 
Budyko's (1956) rough estimation method has produced much more realistic assessments of 1-2 m. Further, UNESCO (1974) found that ET for the southern USA ranges between 0.8 and $1.8 \mathrm{~m}$ during the summer months.

From the above discussion it is apparent that the theoretical basis of these models is weak and largely assumes a linear relationship. Therefore, incorporating a solid theoretical basis into these methods would help to improve our predictive power.

An alternative approach to the above methods is the use of the BATS (Dickinson and Sellers, 1988) or SiB (Sellers et al., 1986) models for global ET estimation. These models are theoretically sound, physically based methods that have been developed for large-scale applications. However, the problem with these models lies in the fact that, currently, data are not available to calibrate or validate the models' differing components. A promising solution to this problem of calibration and verification can, nevertheless, be found in the use of remotely sensed data. Several studies have recently been conducted successfully using satellite data to estimate fluxes (cf. O’Kane, 1991; Running, 1991; Schmugge and Becker, 1991).

\section{Soil moisture}

It is evident from the above discussion of runoff and ET that, depending on the scale of application, a separate modelling approach is needed to estimate soil moisture. For example, Sharma and Luxmoore (1979) used scaling theory and Monteith's (1965) method to determine successfully the soil moisture budget when estimating the water balance of a small watershed in Oklahoma. Similar work has been carried out by Peck et al. (1977), Federer (1979) and Clapp et al. (1983). The data requirements for calibration and validation are so extensive for all these models that they are applicable only to small-scale studies. On the other hand, Thornthwaite's water balance method has been applied extensively to regional or global-scale soil moisture calculation. Willmott et al. (1985), Serafini and Sud (1987) and Mintz and Walker (1993) successfully applied this method to calculate the global soil moisture budget. Gleick (1987) used a modified version of the Thornthwaite method to estimate the water budget of the Sacramento 
basin. Delworth and Manabe (1988) modified Budyko's (1956) method in their soil moisture budget calculation for the globe under $2 \times \mathrm{CO}_{2}$ conditions. In his water balance model, Thornthwaite (1948) introduced a soil-moisture resistance function which is a ratio of the actual and maximum possible soil moisture conditions at the root zone. This function was later modified by Nappo (1975). Nappo assumed that soil moisture is readily available to plants until soil-moisture storage capacity is reduced to $30 \%$. Under storage conditions lower than this, the ability of plants to extract moisture from the soil decreases rapidly. Legates and Willmott (1995) note that owing to the assumption that precipitation would fall every day of the month, ET would be overestimated and runoff underestimated. Further, the assumption of a uniform $15 \mathrm{~cm}$ root zone for worldwide vegetation cover is unrealistic: the depth of grasslands' root zones can be shallower than 15 $\mathrm{cm}$, while tropical forests' root zone depths are usually much deeper than $15 \mathrm{~cm}$. As discussed earlier, the depth of the root zone influences the moisture-holding capacity of the soil which, in turn, affects the soil-moisture function term in the model. Thornthwaite's water budget model assumes a single layer of soil (Legates and Willmott, 1995), which is not realistic. Moreover, it is difficult to acquire detailed information about soil for global-scale studies. However, regardless of these weaknesses, the Thornthwaite method is one of the few models that can be applied to large-scale regional studies.

\section{Conclusions}

Owing to their successful inclusion of biophysical-chemical processes, "physically based" models should be an ideal tool for soil moisture estimation. However, data restrictions make it difficult to apply these sophisticated models to larger-scale studies. Despite this drawback, these models can be used for research and educational purposes. In the mean time, Thornthwaite-type models can be modified, and a more solid theoretical basis can be provided for large-scale applications. Furthermore, as a result of data restrictions and owing to the extensive parameterization scheme, the SiB or BATS-type models are not ready for regional and global-scale studies. The use of remotely sensed data for land surface characterization, model calibration, and 
model validation is quite promising, and more emphasis should be placed on developing proper methods to utilize these data. Additionally, some of the model-building exercises should engage themselves in improving the data archives.

Acknowledgment The author would like to thank Professor D.R. Legates for initiating many thoughtful discussions on soil moisture modelling.

\section{References}

Budyko, M.I. 1956: Heat balance of the earth's surface (trans. N.A. Stephanova). Washington, DC: US Weather Bureau, Office of Climatology.

Butler, D.R. 1986: Evaporation from raindrops on leaves in a cereal canopy: a simulation model. Boundary-Layer Meteorology 36, 39-51.

Caprio, J.M. 1974: The solar thermal unit concept in problems related to plant development and potential evapotranspiration. In Leith, H., editor, Phenology and seasonality modeling, New York: Springer-Verlag, 353-64.

Choudhury, B.J. and Monteith, J.L. 1988: A four-layer model for the heat budget of homogeneous land surfaces. Quarterly Journal of the Royal Meteorological Society 114, 373-98.

Clapp, R.B., Hornberger, G.M. and Cosby, B.J. 1983: Estimating spatial variability in soil moisture with a simplified dynamic model. Water Resources Research 19, 739-45.

Delworth, T.L. and Manabe, S. 1988: The influence of potential evaporation on the variabilities of simulated soil wetness and climate. Journal of Climate 1, 523-47.

Dickinson, R.E. and Sellers, A.H. 1988: Modelling tropical deforestation: a study of GCM landsurface parameterizations. Quarterly Journal of the Royal Meteorological Society 114, 439-62.

Dooge, J.C.I. 1992: Hydrologic models and climatic change. Journal of Geophysical Research 97, 2677-86.

Doorenbos, J. and Pruitt, W.O. 1975: Crop water requirements. Irrigation and drainage. FAO: Rome.

Dunne, T. and Leopold, L.B. 1978: Water in environmental planning, W.H. Freeman: San Francisco.

Federer, C.A. 1979: A soil-plant-atmosphere model for transpiration and availability of soil water. Water Resources Research 15, 555-62.

Garratt, J.R. and Hicks, B.B. 1973: Momentum, heat and water vapour transfer to and from natural and artificial surfaces. Quarterly Journal of the Royal Meteorological Society 99, 680-87.

Gash, J.H.C. 1979: An analytical model of rainfall interception by forests. Quarterly Journal of the Royal Meteorological Society 105, 43-55. 
Gash, J.H.C. and Morton, A.J. 1978: An application of the Rutter model to the estimation of the interception loss from Thetford forest. Journal of Hydrology 38, 49-58.

Gleick, P.H. 1987: The development and testing of a water balance model for climate impact assessment: modeling the Sacramento basin. Water Resources Research 23, 1049-61.

Grimmond, C.S.B. and Oke, T.R. 1991: An evapotranspiration-interception model for urban areas. Water Resources Research 27, 1739-55.

Hargreaves, G.H. 1974: Estimation of potential and crop evapotranspiration. Transactions ASAE 17, 701-704.

Hargreaves, G.H. and Samani, Z.A. 1985: Reference crop evapotranspiration from temperature. Applied Engineering in Agriculture 1, 96-99.

Hughes, D.A. 1994: Soil moisture and runoff simulations using four catchment rainfall-runoff models. Journal of Hydrology 158, 381-404.

Jensen, M.E. and Haise, H.R. 1963: Estimating evaporation from solar radiation. Journal of Irrigation and Drainage Division, ASCE 89, 15-41.

Klemes, V. 1983: Conceptualization and scale in hydrology. Journal of Hydrology $65,1-23$.

Legates, D.R. and Mather, J.R. 1992: An evaluation of the average annual global water balance. Geographical Review 82, 253-67.

Legates, D.R. and Willmott, C.J. 1995: Evaluating the terrestrial water balance from the historical climate record. In Oliver, H.R. and Oliver, S.A., editors, The role of water and the hydrological cycle in global change, New York: SpringerVerlag, 23-58.

Legg, B.J. and Monteith, J.L. 1975: Heat and mass transfer within plant canopies. In de Vries, D.A. and Afgan, N.H., editors, Heat and mass transfer in the biosphere. New York: John Wiley and Sons.

Loague, K. 1990: R-5 revisited. 2. Reevaluation of a quasi-physically based rainfall-runoff model with supplemental information. Water Resources Research 26, 973-87.

_ 1992a: Soil water content at R-5. Part 1. Spatial and temporal variability. Journal of Hydrology 139, 233-51.

— 1992b: Soil water content at R-5. Part 2. Impact of antecedent conditions on rainfall-runoff simulations. Journal of Hydrology 139, 253-61.

Loague, K. and Freeze, R.A. 1985: A comparison of rainfall-runoff modeling techniques on small upland catchments. Water Resources Research 21, 229-48.

Loague, K. and Gander, G.A. 1990: R-5 revisited. 1. Spatial variability of infiltration on a small rangeland catchment. Water Resources Research 26, 957-71.

Luxmoore, R.J. and Sharma, M.L. 1980: Runoff responses to soil heterogeneity: experimental and simulations comparisons for two contrasting watersheds. Water Resources Research 16, 675-84.

Manabe, S. 1969: Climate and ocean circulation. 1. The atmospheric circulation and the hydrology of the earth's surface. Monthly Weather Review 97,739-74.

Massman, W.J. and Dijken, A.V. 1989: Water vapor transfer from a vegetated surface: a numerical study of bulk transfer coefficients and canopy resistance. Boundary-Layer Meteorology 49, 295-307. 
Mather, J.R. 1978: The climatic water budget in environmental analysis. Lexington, MA: Lexington Books.

Milly, P.C.D. 1992: Potential evaporation and soil moisture in general circulation models. Journal of Climate 5, 209-26.

Milly, P.C.D. and Eagleson, P.S. 1987: Effects of spatial variability on annual average water balance. Water Resources Research 23, 2135-43.

Mintz, Y. and Walker, G.K. 1993: Global fields of soil moisture and land surface evapotranspiration derived from observed precipitation and surface air temperature. Journal of Applied Meteorology 32, 1305-33.

Monteith, J.L. 1965: Evaporation and environment. Symposium of the Society of Experimental Biology 19, 205-24.

Myers, T. and Paw, K.T. 1987: Modelling the plant canopy micrometeorology with higher-order closure principles. Agricultural and Forest Meteorology 41, 143-63.

Nappo, C.J. 1975: Parameterization of surface moisture and evaporation rate in a planetary boundary layer model. Journal of Applied Meteorology 14, 289-96.

O’Kane, J.P. 1991: Implications for remote sensing of natural switching from atmospheric-controlled to soil-controlled evaporation or infiltration. In Schmugge, T.J. and Andre, J.-C., editors, Landsurface evaporation: measurement and parameterization, New York: Springer-Verlag, 371-81.

Peck, A.J., Luxmoore, R.J. and Stolzy, J.L. 1977: Effects of spatial variability of soil hydraulic properties in water budget modeling. Water Resources Research 13, 348-54.

Penman, H.L. 1948: Natural evaporation from open water, bare soil, and grass. Proceedings of the Royal Society of London, Series A 193, 120-45.

Pilgrim, D.H. 1983: Some problems in transferring hydrology relationships between small and large drainage basins and between regions. Journal of Hydrology 65, 49-72.

Pilgrim, D.H., Cordery, I. and Bruce, C.B. 1982: Effects of catchment size on runoff relationships. Journal of Hydrology 58, 205-21.

Priestley, C.H.B. and Taylor, R.J. 1972: On the assessment of surface heat flux and evaporation using large-scale parameters. Monthly Weather Review 100, 81-92.

Rind, D., Goldberg, R., Hansen, J., Rosenzweig, C. and Ruedy, R. 1990: Potential evapotranspiration and the likelihood of future drought. Journal of Geophysical Research 95, 9983-10 004.

Rosenberg, N.J., Blad, B.L. and Verma, S.B. 1983: Microclimate: the biological environment, New York: Wiley.

Running, S.W. 1991: Computer simulation of regional evapotranspiration by integrating landscape biophysical attributes with satellite data. In Schmugge, T.J. and Andre, J.-C., editors, Landsurface evaporation: measurement and parameterization, New York: Springer-Verlag, 359-69.

Rutter, A.J., Kershaw, K.A., Robins, P.C. and Morton, A.J. 1971: A predictive model of rainfall interception in forests. I. Derivation of the model from observations in a plantation of Corsician pine. Agricultural Meteorology 9, 367-84.

Schmugge, T.J. and Becker, F. 1991: Remote sensing observations for the monitoring of landsurface fluxes and water budgets. In Schmugge, T.J. and Andre, J.-C., 
editors, Landsurface evaporation: measurement and parameterization, New York: Springer-Verlag, 337-47.

Sellers, P.J. and Lockwood, J.G. 1981: A computer simulation of the effects of differing crop types on the water balance of small catchments over long time periods. Quarterly Journal of the Royal Meteorological Society 107, 395-414.

Sellers, P.J., Mintz, Y., Sud, Y.C. and Dalcher, A. 1986: A simple biosphere model (SiB) for use within general circulation models. Journal of the Atmospheric Sciences 43, 505-31.

Serafini, Y.V. and Sud, Y.C. 1987: The time scale of the soil hydrology using a simple water budget model. International Journal of Climatology 7, 585-91.

Sharma, M.L. and Luxmoore, R.J. 1979: Soil spatial variability and its consequences on simulated water balance. Water Resources Research 15, 1567-73.

Shuttleworth, W.J. 1978: A simplified one-dimensional theoretical description of the vegetation-atmosphere interaction. Boundary-Layer Meteorology 14, 3-27.

— 1979: Evaporation. Report 56. Wallingford: Institute of Hydrology.

— 1991: Evaporation models in hydrology. In Schmugge, T.J. and Andre, J.-C., editors, Land surface evaporation: measurement and parameterization, New York: Springer-Verlag, 93-120.

Shuttleworth, W.J. and Wallace, J.S. 1985: Evaporation from sparse crops - an energy combination theory. Quarterly Journal of the Royal Meteorological Society 111, 839-55.

Sinclair, T.R., Murphy, C.E, and Knoerr, K.R. 1976: Development and evaluation of simplified models simulating canopy photosynthesis and transpiration. Journal of Applied Ecology 13, 813-29.

Stigter, C.J. 1980: Assessment of the quality of generalized wind functions in Penman's equations. Journal of Hydrology 45, 321-31.

Thom, A.S. and Oliver, H.R. 1977: On Penman's equation for estimating regional evaporation. Quarterly Journal of the Royal Meteorological Society 103, 345-57.

Thomthwaite, C.W. 1948: An approach toward a rational classification of climate. Geographical Review 38, 55-94.

UNESCO 1974: Atlas of the world water balance, UNESCO: Geneva.

van Bavel, C.H.M. 1966: Potential evaporation: the combination concept and its experimental verification. Water Resources Research 2, 455-67.

Waggoner, P.E. and Reifsnyder, W.E. 1968: Simulation of the temperature humidity and evaporation profiles in a leaf canopy. Journal of Applied Meteorology 7, 400-409.

Willmott, C.J. 1984: On the evaluation of model performance in physical geography. In Gaile, G.L. and Willmott, C.J., editors, Spatial statistics and models, Dordrecht: Reidel, 443-6o.

Willmott, C.J., Rowe, C.M. and Mintz, Y. 1985: Climatology of the terrestrial seasonal water cycle. Journal of Climatology 5, 589-606.

Wilson, J.D. 1989: Turbulent transport within the plant canopy. In Black, T.A., Splittlehouse, D.L., Novak, M.D. and Price, D.T., editors, Estimation of areal evapotranspiration, Wallingford: IAHS, 43-80. 


\section{Appendix}

\section{Energy balance models}

\section{Penman (1948)}

$$
\lambda E=\frac{s Q_{N}+\gamma E_{a}}{s+\gamma}
$$

and

$$
E_{a}=f(U)\left(e_{s}-e_{a}\right)
$$

where $Q_{N}$ is net radiation, $\gamma$ is the psychrometric constant, $s$ is the slope of the saturation vapor pressure curve, $E$, is actual evapotranspiration, $e_{s}$ and $e_{a}$ are the saturation and actual vapor pressure and $U$ is the wind speed in $\mathrm{km} \mathrm{day}^{-1}$ at $2 \mathrm{~m}$ height. Several methods of $f(U)$ estimation were proposed by Doorenbos and Pruitt (1975), Thom and Oliver (1977) and Stigter (1980).

Doorenbos and Pruitt (1975)

$$
f(U)=0.27(1+U / 100)
$$

Thom and Oliver (1977)

$$
f(U)=0.26(1+U / 100)
$$

Stigter (1980)

$$
f(U)=0.37(1+U / 160)
$$

\section{Van Bavel (1966)}

$$
\lambda E=-\frac{s\left(R_{n}+S\right)+\gamma L B_{v}\left(e_{s}-e_{a}\right)}{s+\gamma}
$$

where $S$ is the slope of the saturation vapor pressure curve, $S$ is soil heat, $R_{n}$ is net radiation, $L$ is the latent heat of vaporization and $B_{v}$ can be expressed as follows:

$$
B_{v}=\frac{\rho_{a} \varepsilon k^{2}}{P} \frac{U}{\left[\ln \left(z / z_{\mathrm{o}}\right)\right]^{2}}
$$


where $k$ is von Karman's constant, $P$ is atmospheric pressure, $\rho$, is the density of moist air, and $E$ is the ratio of the molecular weight of air and water, $z$ is the height above surface and $z_{\mathrm{o}}$ is roughness length.

\section{Priestley-Taylor (1972)}

$$
\lambda E=\alpha \frac{s}{s+\gamma}\left(R_{n}+S\right)
$$

where $\alpha$ is an empirically derived constant, 1.26 .

\section{Interception models}

\section{Thom and Oliver (1977)}

$$
\lambda E=\frac{\Delta Q_{N}+\gamma E_{a}}{\Delta+\gamma(1+n)}
$$

where $Q_{N}$ is net radiation, $\gamma$ is the psychrometric constant, $\Delta$ is the slope of saturation vapor pressure versus the temperature curve for water at air temperature, $n$ is the ratio between aerodynamic and surface resistance and $E_{a}$ is a modified version of the equivalent term in the Penman equation:

$$
E_{a}=13.8\left(e_{s}-e_{a}\right)(1+U / 100) / \ln ^{2}\left(z / z_{o}\right)
$$

where $e_{s}$ and $e_{a}$ are the actual and the saturation vapor pressure measured at a height $z, z_{\mathrm{o}}$ is the estimate of the aerodynamic roughness parameter for the vegetation and $U$ is wind speed.

\section{Gash (1978; 1979)}

$$
\lambda E=\frac{\Delta Q_{N}+\gamma E_{a}}{\Delta+\gamma\left(1+r_{s d} / r_{a}\right)}+I(1-c)
$$

where $r_{a}$ is surface resistance, $r_{s d}$ is stomatal resistance, $I$ is interception loss and $c$ is a correction term. This correction term calculates transpiration under wet conditions. It can be expressed as follows: 


$$
\begin{aligned}
& c=(\Delta+\gamma) /\left[\Delta+\gamma\left(1+r_{s d} / r_{a}\right)\right] \\
& I=P_{s}+n S+(E / R)\left(P-P_{s}\right)
\end{aligned}
$$

where $P$ is precipitation input, $P_{s}$ is the fraction of precipitation in rain storms less than $5 /(1-p), S$ is canopy storage, $n$ is the number of storms with precipitation greater than $5 /(1-p), R$ is the mean rainfall rate in storm conditions, and $E$ is the mean evaporation rate from a totally wet forest canopy in storm conditions.

\section{Single layer}

\section{Monteith (1965)}

$$
\lambda E=-\frac{s\left(R_{n}+S\right)+\rho_{a} C_{p}\left(e_{s}-e_{a}\right) / r_{a}}{(s+\gamma)\left[\left(r_{a}+r_{c}\right) / r_{a}\right]}
$$

where $s$ is the slope of the saturation vapor pressure curve at the mean wet-bulb temperature of the air, $r_{a}$ is atmospheric resistance, $r_{c}$ is canopy resistance, $S$ is soil heat flux, $e_{a}$ is the partial pressure of water vapour in the air, $e_{s}$ is the saturation water vapor pressure, $C_{p}$ is the specific heat of the air at constant pressure, $\rho_{a}$ is the density of moist air and $\gamma$ is the psychrometric constant.

\section{Grimmond and Oke (1991)}

$$
\lambda E=\frac{s\left(Q^{*}+Q_{F}-\Delta Q_{s}\right)+\left(C_{a} V\right) / r_{a}}{\left.s+\gamma\left(1+r_{s}\right) / r_{a}\right)}
$$

where $Q^{*}$ is the net radiation, $Q_{F}$ is anthropogenic heat flux, $\Delta Q_{s}$ is storage heat flux, $C_{a}$ is heat capacity, $V$ is vapor pressure deficit and $r_{a}$ and $r_{s}$ are aerodynamic and surface resistance. 


\section{Multilayer}

\section{A. Integration of crop and soil}

\section{Waggoner and Reifsnyder (1968)}

$$
\lambda E=(V P D)+\theta(\Delta E / \Delta T) C_{p}(\rho / a)
$$

where $V P D$ is the vapor pressure deficit of the air at the canopy top, $\theta$ is air temperature, $a$ is the psychrometric constant and $\Delta E / \Delta T$ is the change of vapor pressure with change in temperature.

\section{Shuttleworth and Wallace (1985)}

$$
\begin{aligned}
& \lambda E=\left(\Delta A_{s}+\rho c_{p} D_{\mathrm{o}} / r_{s a}\right)\left[\Delta+\gamma\left(1+r_{s s} / r_{s a}\right)\right]^{-1} \\
& \lambda E=\left[\Delta\left(A-A_{s}\right)+\rho c_{p} D_{\mathrm{o}} / r_{c a}\right]\left[\Delta+\gamma\left(1+r_{c s} / r_{c a}\right)\right]^{-1}
\end{aligned}
$$

where $\lambda E_{s}$ and $\lambda E_{c}$ are evaporation from the substrate and the plant canopy, respectively ; $A$ and $A_{s}$ are total latent and sensible heat flux from the complete crop and substrate; $D_{\mathrm{o}}$ is the vapor pressure deficit which integrates the concept of transfer resistance between the mean canopy layer and the reference height; $r_{s s}$ is surface resistance at the substrate surface, while $r_{c a}$ is the bulk boundary-layer resistance which controls the transfer between the vegetation surface and the canopy air stream, and $r_{s a}$ is the transfer resistance between the substrate surface and the adjacent boundary layer.

\section{Choudhury and Monteith (1988)}

$$
\lambda E_{v}=\frac{\Delta_{1} R_{v}+\rho C_{p} D_{b} / r_{1}}{\Delta_{1}+\gamma\left(1+r_{c} / r_{1}\right)}
$$

where $R_{v}$ is net radiation at the vegetation surface, $\rho$ is the density of moist air, $C_{p}$ is the specific heat of air, $D_{b}$ is the saturation deficit, $\gamma$ is the psychrometric constant, $r_{1}$ is aerodynamic resistance between the canopy and air, and $r_{c}$ is canopy stomatal resistance.

$$
\lambda E_{s}=\frac{\xi \Delta_{2} R_{s}+\rho C_{p}\left[\Delta_{2}\left(T_{m}-T_{b}\right) / r_{1}\right]+\eta D_{b} / r_{2}}{\Delta_{2}+\gamma_{2}}
$$


where $R_{s}$ is net radiation at the soil surface, $T_{b}$ is the mean air temperature, $T_{m}$ is the temperature at the bottom of the wet soil layer, $r_{1}$ is the resistance of the wet layers proportional to the depth and inversely proportional to thermal conductivity, $\xi$ and $\eta$ are the functions of resistances, and $r_{2}$ is the resistance between the soil surface and the canopy.

\section{B. Crop only}

Sinclair et al. (1976)

$$
\lambda E=L_{i} \frac{\rho_{v s}\left(T L_{i}\right)-\rho_{v i}}{R A_{i}+R S_{i}}
$$

where $L$ is the leaf area index, $R S_{i}$ and $R A_{i}$ are stomatal and aerodynamic resistances and $\rho_{v s}\left(T L_{i}\right)$ is saturated vapor density.

\section{Eddy diffusion models}

\section{Wilson (1989)}

$$
\langle\bar{E}\rangle=\left\langle\overline{W \rho_{v}}\right\rangle
$$

where $W$ is the vertical velocity across the horizontal plane and $\rho_{v}$ is vapor density.

\section{Massman and Dijken (1989)}

$$
\frac{d}{d z}\left(K_{e}(z) \frac{d e}{d z}\right)=\frac{-a(z)\left(e_{f}-e\right)}{r_{b}(z)+r_{s}(z)}
$$

where $z$ is the height above the ground, $e$ is the mean atmospheric vapor pressure within the canopy, and $e_{f}$ is the vapor pressure within the substomatal cavity of the leaves and is assumed to be constant with height. $K_{e}$ is the turbulent diffusivity of water vapor, $a(z)$ is foliage density, $r_{b}(z)$ is the individual leaf boundary-layer resistance, and $r_{s}$ is individual leaf stomatal resistance (all these parameters are a function of height, $z$ ). 


\section{Butler (1986)}

For drops:

$$
\partial E_{d} / \partial \xi=\alpha_{s} \rho\left(q_{d}-q\right) / r_{d}
$$

and for leaves:

$$
\partial E_{l} / \partial \xi=\alpha_{l} \rho\left(q_{l}-q\right) /\left(r_{s}+r_{l}\right)
$$

where $\xi$ is canopy height, and $\alpha_{s}$ and $\alpha_{l}$ are nondimensional area density and nondimensional dry-leaf area density, respectively. $r_{d}, r_{s}$ and $r_{l}$ are resistance terms, $q_{d}$ and $q_{l}$ are the specific humidities of saturated air at drop and leaf temperature, respectively, and $q$ is the specific humidity of the air.

Total flux divergence:

$$
\partial E / \partial \xi=\partial E_{l} / \partial \xi+\partial E_{d} / \partial \xi
$$

\section{Myers and Paw (1987)}

$$
E=2 L_{v} \rho \frac{\left(\bar{q}_{l}-\bar{q}\right)}{r_{b}-r_{s}}
$$

where $L_{v}$ is the latent heat of vaporization, $\rho$ is air density, $r_{b}$ and $r_{s}$ are boundary-layer resistance and stomatal resistance, $q_{l}$ and $q$ are the saturation specific humidity at leaf temperature and the specific humidity of the air.

\section{Rosenberg et al. (1983)}

$$
E=\frac{\left(M_{w} / M_{\mathrm{a}}\right)}{P} \rho_{\mathrm{a}} C_{p} K_{w} \frac{\partial e_{\mathrm{a}}}{\partial z}
$$

where $M_{w}$ and $M_{a}$ are the molecular weight of water vapor and air, $K_{w}$ is the turbulent exchange coefficient for water vapor, $\rho_{a}$ is air density, $C_{p}$ is specific heat at constant pressure, $P$ is atmospheric pressure and $\partial e_{d} / \partial z$ is the vertical gradient of vapor pressure. 


\section{Temperature-based models}

\section{Thornthwaite (1948)}

$$
E T_{p}=16\left(\frac{l_{1}}{12}\right)\left(\frac{N}{30}\right)\left(10 \frac{T_{a}}{I}\right)^{\mathrm{a}_{1}}
$$

where $E T_{p}$ is mm month ${ }^{-1}, l_{1}$, is actual day length (h), $N$ is the number of days in a month, $T_{a}$ is the mean monthly air temperature and $a_{1}$ is defined as

$$
a_{1}=6.75 * 10^{-7} I^{3}-7.71 * 10^{-5} I^{2}+1.79 * 10^{-2} I+0.49
$$

where $I$ is a heat index calculated from the sum of 12 monthly values, $i$, obtained from

$$
i=\left(\frac{T_{a}}{5}\right)^{1.514}
$$

\section{Nappo (1975)}

$$
\begin{aligned}
& E_{a}=E_{p} * \mathrm{M}(\eta) \\
& M(\eta)=1-e^{-56.6(\eta)}
\end{aligned}
$$

where $M(\eta)$ is the moisture availability function. Mintz and Serafini (1984) modified the moisture availability function as follows:

$$
M\left(W, W^{*}\right)=1-e^{\alpha\left(W / W^{*}\right)}
$$

where $W$ is the available soil moisture, $W^{*}$ is the difference between the soil and the moisture in the soil at vegetation wilting point and $\alpha$ is a transformation constant. Serafini and Sud (1987) modified Mintz and Serafini (1984), proposing a soil moisture availability function as follows:

$$
M\left(W, W^{*}\right)=1-e^{\alpha\left(W / W^{*}\right)} /\left(1-e^{-\alpha}\right)
$$

\section{Hargreaves (1974)}

$$
E T_{p}=M F\left(1.8 T_{a}+32\right) C H
$$

where $E T_{p}$ is mm month ${ }^{-1}, \mathrm{MF}$ is a monthly latitude-dependent factor, $T_{a}$ is the mean monthly temperature and $\mathrm{CH}$ is the correction factor 
for relative humidity $(R H)$. $\mathrm{CH}$ is only used when mean daily relative humidity values exceed $64 \%$.

\section{Solar-radiation-based models}

Jensen-Haise (1963)

$$
E T_{p}=R_{s}\left(0.025 T_{a}+0.08\right)
$$

where $E T_{p}$ is $\mathrm{mm}$ day $^{-1}, T_{a}$ is the mean daily temperature and $R_{s}$ is daily total solar radiation ( $\mathrm{mm}$ equivalent of water).

\section{Solar-radiation and temperature-based models}

Hargreaves-Samani (1985)

$$
E T_{p}=0.00094 * R_{a} * t F * t D^{1 / 2}
$$

where $R_{a}$ is the daily extraterrestrial radiation in $\mathrm{mm}$ equivalent of water, $t F$ is mean daily temperature and $t D$ is the difference between maximum and minimum daily temperature. $R_{a}$ is a function of latitude and time of year. 